\title{
Additional endoscopic procedures instead of urgent surgery for retained common bile duct stones
}

\author{
S R CAIRNS, L DiAS, P B COTTON, P R SALMON, AND R C G RUSSELL \\ From the Departments of Gastroenterology, Middlesex Hospital, London and Duke University Medical \\ Center, Durham, N Carolina, USA
}

SUMMARY One hundred and twenty seven patients were treated by nasobiliary drainage, or stenting, to prevent biliary obstruction after endoscopic failure to clear stones from the common bile duct. At presentation, $91(72 \%)$ patients were jaundiced and $39(31 \%)$ had cholangitis. Placement of either a nasobiliary drain or stent was successful in $124(98 \%)$ patients. One hundred and twenty one $(95 \%)$ patients were followed up. Clearance was ultimately achieved endoscopically in 52 and surgically in 25 patients after (mean) 2.4 months. Thirty day mortality was $3 \%$. There were no complications of nasobiliary drainage, but two of 39 patients treated by temporary stents developed cholangitis, both successfully managed by endoscopic duct clearance. Forty two patients unfit for surgery or further endoscopic attempts at duct clearance were followed with stents in situ for a mean 15.9 months (range $2 \cdot 5-37 \cdot 5$ ). Cholangitis developed in four patients and was successfully managed by stent change. These results indicate that longterm stenting can be useful for poor risk surgical patients and that nasobiliary drainage or temporary stenting permits further elective rather than urgent endoscopic or surgical treatment.

Endoscopic sphincterotomy and stone extraction were introduced by Kawai ${ }^{1}$ and Demling ${ }^{2}$ in 1974. Since then, most series have reported successful endoscopic duct clearance in around $85 \%$ of patients. ${ }^{3}$ Failure to clear the duct renders a patient at risk from recurrent obstruction, cholangitis, and pancreatitis. ${ }^{47}$ Indeed, a recent estimate of the increased risk to patients whose bile duct was not cleared of stones showed a statistically significant three-fold increase in morbidity, with major complications occurring in $32 \%$ of patients. ${ }^{7}$ Treatment of retained stones after a failed attempt at endoscopic extraction is often urgent laparotomy with exploration of the bile duct done in patients initially considered at high risk from surgery and referred specifically for endoscopic clearance. Two alternative procedures are available to prevent the complications of retained common duct stones, namely nasobiliary drains $^{89}$ and biliary stents. ${ }^{111}$ The former provides biliary drainage as well as enabling biliary solvents to be perfused to reduce the size of stones, and so

Address for correspondence: Dr Stuart R Cairns, Consultant Physician, Royal Sussex County Hospital, Brighton, Sussex BN2 5BE.

Accepted for publication 20 September 1988. enable passage through the sphincter, while the latter prevents stone impaction. To date these methods of endoscopic biliary drainage have been used as a last resort, without proper evaluation in the management of the retained stone. In this study, the results of the use of these techniques are evaluated to determine their role in the management of stone disease.

\section{Methods}

PATIENTS

During a three year period to February 1987, 624 consecutive patients underwent endoscopic sphincterotomy for symptomatic choledocholithiasis and were prospectively entered onto a computer program (PEDRO). Patients had presented either with cholangitis, jaundice and pain, or a history of biliary colic with clinical or biochemical features of cholestasis. This report is based on 127 patients (45 men, 82 women, aged $26-96$, mean 74.5 years) whose bile duct was not cleared endoscopically at the first attempt. Ninety one $(72 \%)$ patients were jaundiced and $39(31 \%)$ had cholangitis at the time of the initial endoscopy. Thirty six ( $28 \%)$ patients had previously 
undergone cholecystectomy. Biochemical investigation showed mean bilirubin $103 \mu \mathrm{mol} / \mathrm{l}$ (range 5-756).

At the initial endoscopy and after sphincterotomy, complete clearance of the duct is attempted unless stones are considered small enough (less than $0.5 \mathrm{~cm}$ diameter) to pass spontaneously through the sphincterotomy. Endoscopy was done using Olympus equipment, either an Olympus JF-1T10 ( $2.8 \mathrm{~mm}$ working channel) or JF-3.7 duodenoscope $(3.7 \mathrm{~mm}$ working channel). All procedures were covered with parenteral antibiotics (usually mezlocillin) given before endoscopy and for at least 36 hours after the procedure. Endoscopic sphincterotomy was done using the Erlangen sphincterotome and Olympus PSD-2 diathermy. Stones were extracted using baskets (Olympus FG 23Q and FG 22Q) and an occluding balloon (Meditech). An attempt to crush stones using a mechanical lithotripter was successful in several patients but our experience with this device was often disappointing because of difficulty in catching the stone within the basket. Double pig-tail stents (Fig. 1) and nasobiliary drains (Fig. 2) were made from 6.5 French radiopaque polyethylene tubing (PERT-6.5, William Cook Europe). When two stents were placed the second was usually shorter with the upper end placed below the stone to prevent impaction at the papilla. Subsequent attempts at duct clearance were made using baskets and/or balloons with extension of the initial sphincterotomy in 13 patients.

Placement of a nasobiliary drain or stent was attempted in all 127 patients when clearance of the common bile duct was not achieved $(n=119)$ or confirmed by cholangiography $(n=8)$. Failure to clear the duct was because of stone size (usually greater than $1.5 \mathrm{~cm}$ diameter) or narrowed lower common bile duct but in three cases coagulopathy prevented sphincterotomy and no attempt at duct clearance was made. An attempt was made to insert a nasobiliary drain in 49 and stent in 78 patients at the initial endoscopy (Fig. 3). Nasobiliary drains were more often used in the early part of the series but the practice changed as stents were introduced. Nasobiliary drains were often placed when there was doubt about duct clearance, so that a nasobiliary
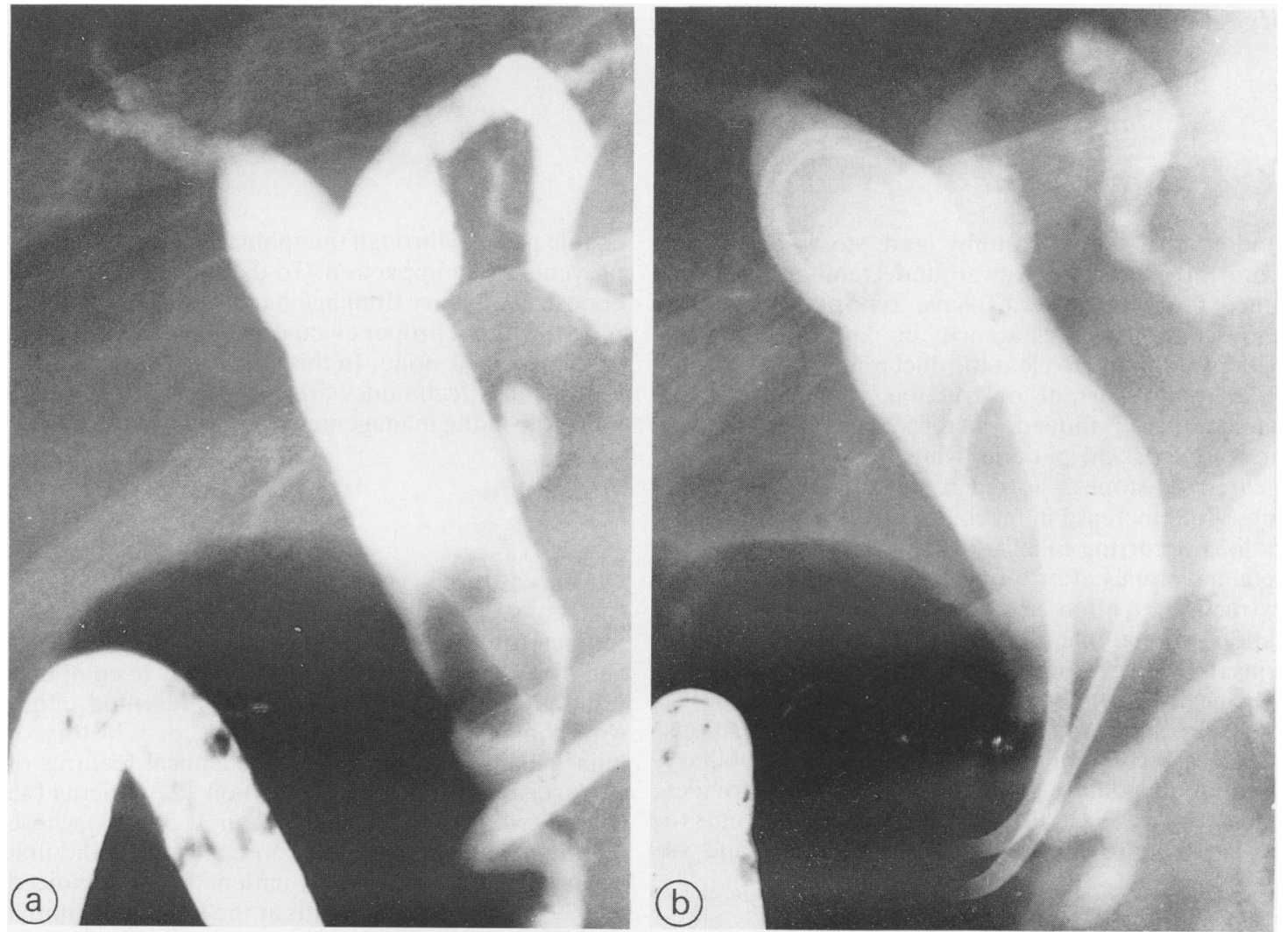

Fig 1 (a) Retained common bile duct stone; (b) two 6.5 French double pig tail stents around the stone. 


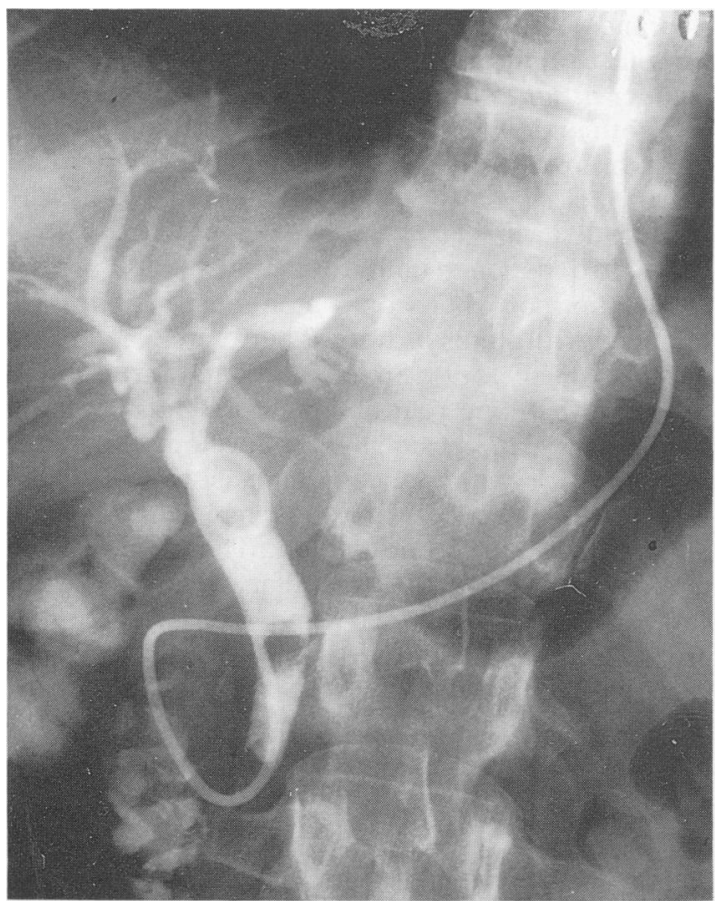

Fig $2 \quad 6 \cdot 5$ French nasobiliary drain placed above a stone in the common bile duct.

cholangiogram could be performed with optimal $x$ ray equipment within the radiology department the next day.

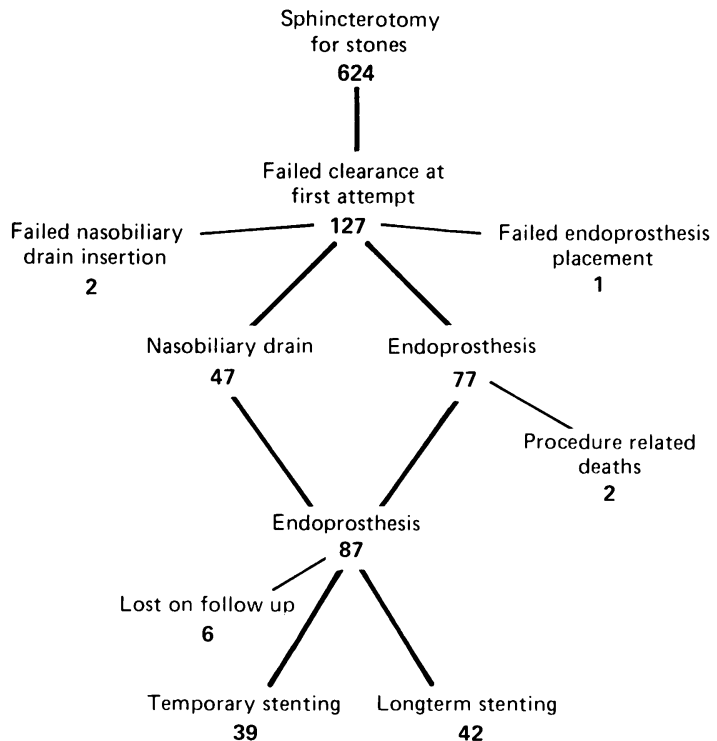

Fig 3 Outline of treatments given to patients presenting with choledocholithiasis.
Follow up was obtained from the referring consultant and the patient's general practitioner and was complete in all patients treated using a nasobiliary drain and obtained from 84 of 90 patients in whom placement of a stent was attempted. Follow up information was obtained to determine biliary and pancreatic complications. Stents were placed in six patients lost to follow up.

NASOBILIARY DRAINAGE

Insertion of a nasobiliary drain was attempted in 49 patients (M/F 24/25) ranging in age from 27-92 years (mean 69). Seven patients had previously had cholecystectomy. Ten patients presented with cholangitis and 22 were jaundiced at the time of the initial endoscopy. Bilirubin concentration ranged from 5-756 $\mu \mathrm{mol} / \mathrm{l}$ (mean 95). Twelve patients initially treated by nasobiliary drainage subsequently had stents placed when a further attempt at endoscopic clearance failed, they are included below in the group of patients given stents.

TEM PORARY STENTING

Follow up was obtained on 39 patients (M/F 14/25) ranging in age from 26-93 years (mean 71) treated with stents as a temporary measure before endoscopic or surgical clearance. Fifteen patients had had cholecystectomy between one month and 29 years ago (mean 4.4) and one patient a Bilroth II gastrectomy. Fourteen patients had presented with cholangitis and 20 were jaundiced at the time of the initial endoscopy. Serum bilirubin concentrations ranged from $10-572 \mu \mathrm{mol} / \mathrm{l}$ (mean 117).

LONGTERM STENTING

Forty two patients (M/F 13/29) ranging in age from 72-93 years (mean 83 ) unfit for surgery with a poor expectation of endoscopic stone extraction were treated with stents as a definitive therapy. Fourteen had undergone cholecystectomy between 0.5 and 32 years (mean 9.8) before endoscopy and four had previously had Bilroth II gastrectomy. Twenty five patients were jaundiced and 16 had cholangitis at the time of the initial endoscopy. Serum bilirubin concentrations ranged from 5-407 $\mu \mathrm{mol} / \mathrm{l}$ (mean 103).

\section{Results}

Clearance of the bile duct was achieved at the first attempt in $497(80 \%)$ of 624 patients. Failure to clear the duct was because of stone size in all but three patients in whom sphincterotomy and clearance was not attempted because of coagulopathy.

NASOBILIARY DRAINAGE

Placement of a nasobiliary drain succeeded in 47 
(96\%) of 49 patients. Successful endoscopic clearance was later achieved in one and uncomplicated surgical clearance in the other patient in whom a drain could not be placed. A subsequent nasobiliary cholangiography in eight patients showed no residual stones. A second attempt at endoscopic clearance succeeded in 22 patients but failed in 12 who were immediately treated by stenting. Further endoscopic attempts were deemed inappropriate in five patients because up to three attempts at endoscopic clearance had failed (three patients) and difficult access to papilla in a duodenal diverticulum (one patient) and referring surgeon's preference for laparotomy with cholecystectomy in a patient aged 89 years; all had an uncomplicated surgical clearance of the bile duct with a drain in situ. There were no deaths nor major complications seen in patients given nasobiliary drainage either during drainage or after endoscopic or surgical clearance.

\section{STENTING}

An attempt to place a stent in 90 patients was successful in $89(99 \%)$. Impaction of a stone at the papilla prevented stent placement in one patient who subsequently underwent uncomplicated laparotomy with stone removal. There were two procedure related deaths - one patient aged 90 years, died after a respiratory arrest during endoscopic placement of a stent and the second patient aged 96 years, died 10 days after stent placement from haematemesis presumed related to the sphincterotomy. Follow up on 81 of the remaining 87 patients was obtained. The outcome of 39 patients stented before endoscopic or surgical clearance (temporary stenting) and 42 considered unfit for surgical or further endoscopic attempts at clearance treated by stenting as definitive treatment (longterm stenting) is described below.

\section{TEM PORARY STENTING}

Thirty nine patients were stented for between $0 \cdot 1$ and 16 months (mean 2.4 ) before successful duct clearance. Twenty patients were stented for more than one month and $\mathbf{1 3}$ for more than two months. One patient spontaneously cleared a stone and stent from the bile duct. Surgical clearance was achieved in 18 patients. Thirteen of the 18 patients treated surgically had not previously undergone cholecystectomy. Indications for surgery were presence of gall bladder stones in patients 50 years or younger (five patients), multiple or large stones $(2-4 \mathrm{~cm}$ diameter) that could not be extracted endoscopically (11 patients), and stone(s) above a narrowed lower common bile duct (two patients). There was one postoperative death from a cerebrovascular accident but no other complications in the remaining patients treated surgically after stent insertion. A further attempt at endoscopic clearance was successful in 20 patients and was without complication. Two patients (both with gall bladder in situ) developed cholangitis whilst stented and both underwent successful endoscopic clearance of the bile duct with resolution of cholangitis.

\section{LONGTERM STENTING}

Forty two patients unfit for surgery with a poor expectation of endoscopic stone extraction were followed with stents in situ for between 2.5 and 37.5 months (mean 15.9). Sixteen patients were stented for more than one year and eight patients for more than two years. Cholangitis developed in four patients (one with previous cholecystectomy) and was treated successfully by stent change in three and antibiotics alone in one patient. There were seven non-biliary deaths and no biliary related deaths. Deaths occurred between 0.8 and 33 months after the procedure and were the result of myocardial infarction (two), disseminated carcinoma (three), bronchopneumonia (one), and road traffic accident (one). Serum liver function tests were available in 13 patients at the end of follow up and were normal in all.

\section{OVERALL RESULTS}

Endoscopic clearance was achieved in $88 \%$ (548/624) of patients. Clearance was achieved surgically in $4 \%$ $(25 / 624)$ and longterm stenting was required in $7 \%$ $(42 / 624)$ of patients. Six patients $(1 \%)$ with stents in situ could not be traced. After endoscopic or surgical treatment, 30 day mortality was $3 \cdot 1 \%(4 / 127)$ with one postoperative, one per, one postendoscopic death, and death caused by myocardial infarction 25 days after stent placement in one patient.

\section{Discussion}

Failure to ensure duct clearance is followed by a higher morbidity and mortality than when duct clearance is confirmed. ${ }^{57}$ Indeed, a recent estimate showed a statistically significant three-fold increase in major complications after initial failure of endoscopic duct clearance. ${ }^{7}$ Small stones will often pass spontaneously after sphincterotomy yet failure to clear the duct predisposes a patient to recurrent biliary obstruction, cholangitis, and pancreatitis. Nasobiliary drains ${ }^{89}$ and stents ${ }^{101}$ to prevent biliary obstruction by retained common duct stones have previously been reported in small numbers of patients but there has until now been no systematic evaluation about their use as a temporary measure or definitive treatment for patients unfit for surgery.

In the presence of a retained stone the placement of a nasobiliary drain confers several benefits: first, the biliary tree is drained, second, it provides a means for serial cholangiography to determine the efficacy 
of solvent infusion and finally placement of a nasobiliary drain will provide a means for radiological imaging of the stone enabling accurate focusing for such treatments as extracorporeal shock wave lithotripsy. Insertion of a nasobiliary drain was achieved in $96 \%$ of patients and was without complication. Insertion of the drain resulted in drainage of the biliary tree with immediate resolution of jaundice and cholangitis and permitted repeat cholangiography without endoscopy for patients with unconfirmed duct clearance. Patients with a nasobiliary drain did report pharyngeal discomfort and it was partly for this reason that stents were preferred in the later part of the series. Insertion of a stent also permitted patients to go home and fully recover from an episode of biliary obstruction before further attempts to clear the biliary tree. We prefer double pigtail 6.5 Fr stents to the straight 10 Fr stent, because straight stents may be more likely to spontaneously dislodge out of the biliary tree and placement of a 10 Fr stent would require changing to a larger channel duodenoscope. We believe that the stents are functioning primarily by splinting the duct and allowing bile to flow around the stones rather than draining bile through the stent.

Stent insertion was successful in $99 \%$ of patients and was always followed by immediate resolution of jaundice. Cholangitis developed in two patients $(5 \%)$, both with gall bladder in situ, within two months of stent placement and both were successfully treated at a further endoscopy by duct clearance. All but one patient temporarily stented had clearance of the duct without complication. The single complication occurred in a patient aged 88 years who had remained well after stent placement but died from a cerebrovascular accident after what we believe was an unnecessary elective cholecystectomy and bile duct exploration.

Longterm stenting of 42 patients unfit for surgery or further endoscopic attempts was associated with recurrence of cholangitis in four $(9.5 \%)$ - cholangitis was successfully managed by stent change and antibiotics in all cases. Clearly, longterm stent placement is not an ideal treatment for duct stones but new techniques such as extracorporeal shock wave lithotripsy, ${ }^{12}$ pulsed laser lithotripsy, ${ }^{13}$ and electrohydraulic shock wave lithotripsy ${ }^{1+16}$ may be able to fragment stones and so facilitate stone extraction. Initial reports of bile duct irrigation with solvents were encouraging ${ }^{1718}$ but our experience of infusing methyl tert-butyl ether (MTBE) has been disappointing because of toxicity. The methods for providing biliary drainage reported in this series will serve to complement the developing techniques of stone disruption by permitting elective application of the preferred method of stone disruption.
We have shown that nasobiliary drain and stent insertion is easy, gives immediate biliary drainage and is safe. Stents and drains can be passed through diagnostic duodenoscopes (working channel $2.8 \mathrm{~mm}$ ) with simple, readily available equipment. We recommend that stents or a drain be placed in the biliary tree whenever stones ( $>5 \mathrm{~mm}$ diameter) cannot be removed endoscopically or there is doubt about duct clearance. The results of this series show that nasobiliary drainage or temporary stenting add, what we believe is, a new dimension to the management of stone disease and malignant obstruction by permitting further elective endoscopic or surgical therapy and so obviate urgent surgery. Furthermore, longterm stenting can provide a useful treatment for poor risk surgical candidates.

These data were published as an Abstract in Gut 1987; 28: A 1371 .

\section{References}

1 Kawai K, Akasaka Y, Murakami M, Tada M, Kohli Y, Nakajima M. Endoscopic sphincterotomy of the ampulla of Vater. Gastrointest Endosc 1974; 20: 148-51.

2 Classen M, Demling L. Endoskopische Sphinkterotomic der Papilla Vateri Und Steinextraktion aus dem Ductus choledochus. Dtsch Med Wochenschr 1974; 99: 496-7.

3 Cotton PB, Endoscopic management of bile duct stones; (apples and oranges). Gut 1984; 25: 587-97.

4 Davidson BR, Neoptolemos JP, Carr-Locke DL. Endoscopic sphincterotomy for common bile duct calculi in patients with gall bladder in situ considered unfit for surgery. Gut 1988; 29: 114-20.

5 Neoptolemos JP, Carr-Locke DL, Fossard DP. Results of a prospective study of a pre-operative endoscopic sphincterotomy versus surgery alone for common bile duct stones. Br Med J 1987; 294: 470-4.

6 Martin DF, McGregor JC, Lambert ME; Tweedle DEF. Stone extraction after endoscopic sphincterotomy - an active policy is best [Abstract]. Gut 1986; A 1360-1.

7 Neoptolemos JP, Davidson BR, Shaw DE, Lloyd D, Carr-Locke DL, Fossard DP. Study of common bile duct exploration and endoscopic sphincterotomy in a consecutive series of 438 patients. Br J Surg 1987; 74: 916-21.

8 Cotton PB, Burney PG, Mason RR. Transnasal bile duct catheterisation after endoscopic sphincterotomy: a method for biliary drainage, perfusion and sequential cholangiography. Gut 1979; 20: 285-7.

9 Classen M, Hagenmuller F. Biliary Drainage. Endoscopy 1983; 15: 221-9.

10 Cotton PB, Forbes A, Leung JWC, Dineed L. Endoscopic stenting for long-term treatment of large bile duct stones, 2-5 year follow-up. Gastrointest Endosc 1987; 33: $411-2$.

11 Sicgl JH, Yatto RP. Biliary endoprostheses for the management of retained common bile duct stones. Am J Gastroenterol 1984; 79: 50-4. 
12 Sauerbruch T, Delius M, Paumgartner G, et al. Fragmentation of gallstones by extracorporeal shock waves. N Engl J Med 1986; 314: 818-22.

13 Lux G, Ell Ch, Hochberger J, Muller D, Demling L. The first successful endoscopic retrograde laser lithotripsy of common bile duct stones in man using a pulsed Neodymium-YAG laser. Endoscopy 1986; 18: 144-5.

14 Hwang M, Lee H, Lin J, Yang J, Yueh S. Transcholecystic endoscopic choledocholithotripsy: successful management of retained common bile duct stone. Endoscopy 1987; 19: 24-7.

15 Silvis S, Siegel J, Hughes R, Keton R, Sievert C, Sivak
M. Use of electrohydraulic lithotripsy to fracture common bile duct stones. Gastroenterology 1986; 32: $155-6$.

16 Koch H, Rosch W, Walz V. Endoscopic Lithotripsy in the common bile duct. Gastrointest Endoscopy 1980: 26, 1: $16-8$.

17 LaFerla G, McCulloch A, Murray W. In vivo choledocholitholysis using MTBE. Br J Hosp Med 1987; 74: $163-4$.

18 Neoptolemos J, Hofmann A, Moussa A. Chemical treatment of stones in the biliary tree. Br J Surg 1986; 73: 515-24. 